\title{
Hypothesis Research Training Quality Award
}

This year marks the inaugural offering of the Hypothesis Research Training Quality Award. This award is intended to recognize quality (online) trainings that cover the conduct or support of research and were offered to health sciences librarians between August 2016-August 2018.

The scope/criteria for this award include:

- Training sessions created by an individual or team of practitioners.

- Training topic concerning the conduct or support of research.

- Training must have been offered to health sciences librarians in the two years prior to the nomination deadline.

- Training session must be currently available online.

Qualifying trainings were evaluated based on a rubric that included: audience, learning objectives, relevance to profession, accessibility \& design, command of subject matter, and topical focus. Many thanks to those who participated in the peer review process of these trainings. Awards were available for three trainings and the following were awarded following review:

1st place - 8 Tips for Using Metrics in Research Evaluation

- Karen Gutzman - Impact \& Evaluation Librarian, Galter Health Sciences Library, Northwestern University, Chicago IL

- Patricia L. Smith - Senior Engagement Manager, Altmetric, Chicago IL

- Kristi L. Holmes - Director, Galter Health Sciences Library, Northwestern University, Chicago IL

This webinar offers librarians a quick, practical way to stay on top of the up-andcoming area of research evaluation and the role librarians can play in it. Attendees will learn how to easily transform their skills in expert searching and metadata into the valuable skills needed in the research evaluation process. Presenters address various types of publication data, review categories of bibliometric indicators, highlight the uses of alternative metrics, cover data sources and tools, and touch on best practices for evaluation.

Available at: http://www.medlib-ed.org/products/1535/8-tips-for-using-metrics-inresearch-evaluation-recording 
2nd place - Community Health Assessment Tools

- Dana Abbey - Associate Professor, National Network of Libraries of Medicine, MidContinental Region, Strauss Health Sciences Library, Anschutz Medical Campus, Aurora CO

There are numerous factors that have the potential to influence the health of your community members including quality of life, health behaviors, utilization of and access to health care, social and economic factors, and the physical environment. In this webinar participants will: 1) learn how to utilize tools for researching these factors at the local level; 2) identify authoritative health information resources for program planning; and 3 ) identify potential community partners.

Available at: https://nnlm.gov/class/community-health-assessment-tools/6759

3rd place - Creating a Campus-Wide Research Data Services Committee (Parts $1 \& 2$ )

- Amy Koshoffer - Science Informationist, UC Libraries, University of Cincinnati, Cincinnati $\mathrm{OH}$

- Renaine Julian - Associate Director for STEM Libraries, Florida State University Libraries, Florida State University, Tallahassee FL

- Cinthya Ippoliti - University Librarian and Director, Auraria Library, University of Colorado Denver, Denver CO

- Betty Rozum - Research Data Librarian, Merrill-Cazier Library, Utah State University, Logan, UT

- Christine Kollen - Data Curation Librarian, Office of Digital Innovation \& Stewardship, Main Library, The University of Arizona, Tucson AZ

- David Minor - Program Director for Data Curation, UC San Diego Library, University of California at San Diego, La Jolla CA

This two-part webinar covers how academic libraries are taking the lead in developing cross-campus collaborations in establishing research data committees to spearhead institutional efforts related to data stewardship and digital projects. This webinar session leads participants through the various steps needed in order to initiate a similar effort within their institutional context.

Available at: https://nnlm.gov/class/creating-campus-wide-research-data-servicescommittee-part-1-building-bridges-and-planting

We are excited to present these as excellent continuing education opportunities for health sciences librarians! 